\title{
Will the Aviation Industry Have a Bright Future after the COVID-19 Outbreak? Evidence from Chinese Airport Shipping Sector
}

\author{
Jingxuan Liu ${ }^{1}$, Ping Qiao ${ }^{2}$ **(D) Jian Ding ${ }^{3}$, Luke Hankinson ${ }^{1}$, Elodie H. Harriman ${ }^{1}$, \\ Edward M. Schiller ${ }^{1}$, Ieva Ramanauskaite ${ }^{1}$ and Haowei Zhang ${ }^{4}$ \\ 1 Business School, University of Sydney, Sydney, NSW 2006, Australia; jliu5955@uni.sydney.edu.au (J.L.); \\ lhan8015@uni.sydney.edu.au (L.H.); ehar3345@uni.sydney.edu.au (E.H.H.); \\ esch7206@uni.sydney.edu.au (E.M.S.); iram2687@uni.sydney.edu.au (I.R.) \\ 2 School of Management and Economics, Beijing Institute of Technology, Beijing 100081, China \\ 3 College of Economics and Management, Tianjin University of Science and Technology, Tianjin 300547, China; \\ chante@mail.tust.edu.cn \\ 4 School of Chemical and Biomolecular Engineering, University of Sydney, Sydney, NSW 2006, Australia; \\ hzha7230@uni.sydney.edu.au \\ * Correspondence: ping.q.0306@gmail.com
}

Received: 24 June 2020; Accepted: 6 November 2020; Published: 11 November 2020

\begin{abstract}
Due to the lockdown regulations worldwide during the COVID-19 pandemic, the global aviation industry has been severely hit. This study focuses on the volatility estimation of stock indexes in the Chinese Airport Shipping Set (ASS) at industry-enterprise levels and identifies possible business behavior that may cause fluctuating differences. Depending on the Generalized Autoregressive Conditional Heteroskedasticity (GARCH) model, text mining method and Word Cloud Views, results show that (1) the holistic volatility of Airport Shipping Set Index (ASSI) increases relative to the pre-COVID period; (2) volatility of airport stocks has crucial differences, while the volatility of shipping stocks is similar; (3) there are different responses to the pandemic between Shenzhen Airport and Shanghai Airport shown in their semiannual financial reports. Compared to the latter, the former had a more positive attitude and took various measures to mitigate risks, providing evidence of the volatility differences between firms.
\end{abstract}

Keywords: COVID-19; financial risk management; stock price returns; stock volatility; airline industry; at industry-enterprise levels

\section{Introduction}

The 2019 outbreak of COVID-19 is still ongoing at the time of writing and continues to present a threat to public health and the global economy (Huang et al. 2020; Yue et al. 2020a, 2020b). As the pandemic overwhelmed many nations' healthcare systems, strict public health measures have been implemented globally (Chin et al. 2020; Fan et al. 2020; Liu et al. 2020b). Such measures have harmed many businesses but have been nearly cataclysmic in the airline industry (Donthu and Gustafsson 2020). Nations including Australia, China, South Korea and New Zealand have to adopt an economic shutdown strategy in order to flatten the curve of infection (Chin et al. 2020; Qiu et al. 2020; Shaked and Orelowitz 2020; Slater 2020; Wang et al. 2020). The International Air Transport Association (IATA) estimates dire times ahead for airlines. According to their reports, revenue passenger kilometers (RPK) will be down 38\% in 2020 compared to 2019 (Pearce 2020). Even though the rate of infection has been stabilized in China by the end of March, COVID-19 had already spread to up to 150 countries (Australian Department of Health 2019). The impacts of COVID-19 so far appear to be unprecedented. 
As of early June, The United States of America (USA) has recorded the largest number of cases with over two million people infected, whereas Brazil, Russia, The United Kingdom, Spain, India and Italy trail behind, each recording between 200,000-775,000 cases (Worldometer 2020). The current numbers suggest that this will continue deeper into the year. State aid has so far been the mechanism by which airlines have been coping with declines in demand (Gössling et al. 2020). Most global airlines have approximately three months of liquidity, which seems to have suffered one of the hardest hits, as demands drop heavily and profitability will cease (Claussen et al. 2018). Although previous research studied the moderating role of COVID-19 in oil price risk exposure of the airline industry and found that this sector benefited from lower oil prices (Akhtaruzzaman et al. 2020a) which provided some offset with lower costs (Pearce 2020), it is crucial to subsequently investigate the financial impact and risk-mitigating policies (Goodell 2020), helping airlines to alleviate the crisis, find a way out of their current dilemmas and achieve their development in the long term.

To meet the goal, this article first investigates the volatility of stock indexes in the Airport Shipping Set (ASS) in China. The reasons for using stocks of the airline sector in China rather than focusing on global aviation are that, first, due to the differences among the trading market, time and currencies, it is hard to integrate all the aviation stocks worldwide, that, second, the pandemic has been controlled in China and shipping is gradually recovering. With regard to the first investigation of stock volatility, facing changes (liquid decrease relating to revenue and profit), investors normally choose to sell off the stock, causing indexes to slump and causing significant volatility. Extant literature about volatility estimation focuses on using Autoregressive conditional heteroskedasticity \& Generalized Autoregressive Conditional Heteroskedasticity (ARCH \& GARCH) or its family to estimate the volatility of stock indexes or to compare the predictable effects among various GARCH type models. For example, Akhtaruzzaman et al. (2020c) applied VARMA $(1,1)$ DCC-GARCH model into financial contagion during COVID-19 crisis, while Akhtaruzzaman et al. (2020b) examine whether gold is a haven asset in different stages of the COVID-19 crisis within the DCC-GARCH model. Prior research paid more attention to the stock index volatility at a macro-level, or in an individual enterprise. However, only focusing on stock volatility cannot arrive at the research purpose, as firms' management and operation are the keys to alleviate crisis hits and realize long-term development. Investors are more likely to invest in those firms with high performance which is related to firms' activities and business (e.g., Han et al. 2019; He and Harris 2020; Liu et al. 2020a). Considering this situation, the paper extends volatility research into the management and operation of businesses. More specifically, by comparing volatility differences among different firms in an identical industry, we investigate differences in operation and management, particularly risk management after the COVID-19 outbreak, which expands research boundaries of financial volatility into management.

To combine research on stock volatility with firms' management and operation in the airline industry, a single method (GARCH model) seems pale. Inspired by Combination Principles of TRIZ (Latin: Teoriya Resheniya Izobreatatelskikh Zadatch) theory that is used to solve invention problems in physics and chemistry, we apply the Combination Principles to combine the GARCH model and the text mining method, a method that can mine high-frequent keywords of management and operation measures in financial reports after the COVID-19 outbreak, and then show these measures' differences through Word Cloud. The combination extends natural science principles into the financial and managerial areas. The rest of the paper is organized as follows: Section 2 discusses our processes for collecting sample data and research methodology (ARCH \& GARCH models and the text mining); Section 3 introduces the empirical results, including volatility estimations of the holistic Airline Shipping Set Index, volatility estimations of the stock index in every company and word cloud comparison between Shenzhen Airport and Shanghai Airport; Section 4 presents the discussion while Section 5 concludes the paper. 


\section{Data and Methods}

\subsection{Data}

For the data selection and processing, all the original data are cited from Eastmoney Securities, a Chinese Internet financial securities company. The data used in ARCH and GARCH Models are the daily closing prices from 31 August 2016 to 1 September 2020, which corresponds to a total of 971 observations of the Airport Shipping Set. The actual trading dates exclude public holidays and weekends. The data are publicly available online at https://www.eastmoney.com/. There are twelve airline-related firms in the Airport Shipping Set. The selected sample firms are Shenzhen Airport, Baiyun Airport, Shanghai Airport, Xiamen Airport, China Southern Airlines, China Eastern Airlines, Spring Airlines, China Express, Air China, Juneyao Airlines, Hainan Airlines Holding Co. Ltd. (Haikou city, China) and CITIC Offshore Helicopter Co., Ltd. (Shenzhen city, China).

\subsection{Methods}

To estimate the volatility of stock indexes in Chinese ASS, we combine ARCH \& GARCH Models with the text mining method. The former can estimate return volatility at the industrial level, while based on analysis of corporate annual reports, the latter can identify intrinsic factors of volatility differences at the micro-enterprise level. Moreover, volatility estimations and text mining are conducted by software RStudio 4.0.2.

\subsubsection{ARCH and GARCH Models}

The returns are calculated by taking the natural logarithm of the ratio of two consecutive prices. Figure 1 illustrates the price return rates (Katsiampa 2017).

$$
r_{t}=\ln \left(\frac{p_{t}}{p_{t-1}}\right)
$$

where $r_{t}$ is the return rate at time $t, p_{t}$ is the daily adjusted closing prices on day $t$.

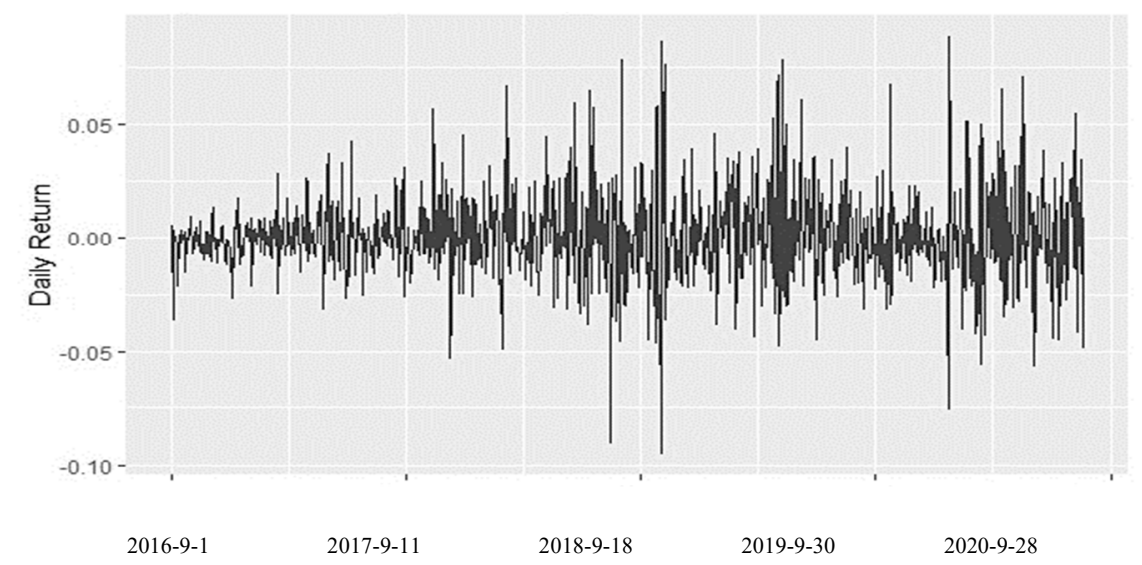

Figure 1. Distribution of Log Returns in the Airport Shipping Set (31 August 2016-1 September 2020).

As for volatility estimation, Engle (1982) offered to model conditional volatility via the Autoregressive Conditional Heteroscedasticity $(\mathrm{ARCH})$ process, which is a function of lagged squared residuals. The general form of the model is:

$$
\begin{gathered}
\sigma_{t}^{2}=\alpha_{0}+\sum_{i=1}^{q} \alpha_{i} \varepsilon_{t-i}^{2} \\
\left(\alpha_{0}>0, \alpha_{i} \geq 0(i=1,2, \ldots, q), \sum_{i=1}^{q} \alpha_{i}<1\right)
\end{gathered}
$$

where $\alpha_{0}$ is mean, $\alpha_{i}$ is conditional volatility and $\varepsilon_{t-i}$ is white noise representing residuals of time series. 
However, to overcome the weaknesses of the inability to exhibit volatility clustering, Bollerslev (1986) revised the ARCH models and proposed the symmetric Generalized Autoregressive Conditional Heteroscedasticity (GARCH) model that synchronized both lagged squared residuals and lagged variances. The formula of the model is:

$$
\begin{gathered}
\sigma_{t}^{2}=\omega+\sum_{j=1}^{q} \alpha_{j} \varepsilon_{t-j}^{2}+\sum_{i=1}^{p} \beta_{i} \sigma_{t-j}^{2} \\
\left(\alpha_{0}>0, \alpha_{i} \geq 0(i=1,2, \ldots, q), \beta_{i} \geq 0(i=1,2, \ldots, p), \sum_{i=1}^{q} \alpha_{i}+\sum_{i=1}^{q} \beta_{i}<1\right)
\end{gathered}
$$

where $i=1,2, \ldots p$, conditional volatility, $\omega, \alpha_{j}, \beta_{i}$ are non-negative constants with $\alpha_{j}+\beta_{i}<1$. $\varepsilon_{t-j}$ is residuals and it is lagged conditional volatility. Both ARCH and GARCH models depend on an assumption that all of the shock impacts on volatility have asymmetric distributions. Based on the minimum values of Akaike Information Criterion (AIC), Bayesian Information Criterion (BIC), and Hannan-Quinn Criterion (HQ) (details are shown in Section 3), we use the symmetric GARCH $(1,1)$ model to measure the volatility of stocks (Bollerslev 1986; Katsiampa 2017; Ardia et al. 2019).

Moreover, Value-at-Risk (VaR) as a risk measurement method answers the question "at a given confidence level (say 95th or 99th percentile), what is the predicted financial loss over a given time horizon?" (Chen et al. 2019). The VaR method is used to measure the potential losses of a portfolio. It reveals the worst expected loss within a given confidence interval over a holding period. The formula is:

$$
\begin{aligned}
& \operatorname{Pr}(\Delta p \Delta t \leq-V a R)=\alpha \\
& \operatorname{VaR}_{(t+1 \mid t)}=F(\alpha)_{\hat{\alpha}_{(t+1 \mid t)}}
\end{aligned}
$$

The variable $\Delta p$ is the value differences of a portfolio within $(1-\alpha)$ confidence interval over the $\Delta t$ holding period, indicating that the loss is greater than VaR in $\alpha \% . F(\alpha)$ is the corresponding quantile of the assumed distribution and $\hat{\alpha}_{(t+1 \mid t)}$ is the forecast of the conditional standard deviation at time $t+$ 1 given the information at time $t$ (Angelidis et al. 2004). In this study, to calculate VaRs, we assume the 95th percent losses of the distribution of profit and loss.

\subsubsection{Text Mining Method}

To identify the reasons for different volatility between firms in ASS, we employ the text mining method to analyze semiannual financial reports, which helps us to mine high-frequency keywords related to the pandemic. The text mining method attempts to extract meaningful information from texts using text preprocessing, text mining/processing/analysis and actionable intelligence (He et al. 2013; Heimerl et al. 2014; Meyer et al. 2008). In the preprocessing phase, we transform the raw material into a usable format, mainly by filtering and integrating paragraphs within an "epidemic" into an Excel file. Subsequently, we applied text mining techniques to do word segmentation, remove stop words and conduct word frequency statistics. Finally, we use the Word Cloud to do feature analysis, which helps us find differential outcomes caused by COVID-19 at the firm-levels.

\section{Results}

\subsection{Empirical Results of the Airport Shipping Set Index}

\subsubsection{Empirical Results}

Table 1 reports the statistical description for daily observations of the Airport Shipping Set Index (ASSI) that contains; mean, median, max, min, skewness, kurtosis and $p$-value results. The mean of ASSI is $0.09 \%$ with a standard deviation of 0.0203 . There is a gap between the max $(0.0887)$ and $\min$ $(-0.0950)$, indicating the high variability of price changes. Normally, distributed series skewness must be 0 and kurtosis is around 3 . The skewness in our results is 0.3766 positively skewed, implying that the distribution has a long right tail and a deviation from normality. Besides, the ASSI returns are platykurtic caused by kurtosis statistics of 2.6742 that is less than the normal value of 3 . Regarding the 
Jarque-Bera test, the $p$-value is significant at the $1 \%$ level, which means the null is rejected and the hypothesis is accepted that returns are not normally distributed. Consequently, all the pre-mentioned statistical analysis gives more support to the suitability of applying ARCH and GARCH models for our data.

Table 1. Descriptive Statistics (971 Observations).

\begin{tabular}{cccc}
\hline Statistical Indicators & Value & Statistical Indicators & Value \\
\hline Mean & 0.0009 & Kurtosis & 2.6742 \\
Median & -0.0004 & Maximum & 0.0887 \\
Std & 0.0203 & Minimum & -0.0950 \\
Skewness & 0.3766 & Jarque-Bera & $314.9^{* * *}$ \\
\hline \multicolumn{4}{c}{ Note: ${ }^{* * *}$ represents the significance at the $1 \%$ level. }
\end{tabular}

Moreover, log-returns during 2016-2020 are represented in Figure 1. We can observe that volatility changes tend to cluster financial returns over time, which is an indicator of long memory (See Figure 1). Namely, large changes tend to be followed by large changes, and vice versa-the small changes are followed by small changes.

An Augmented Dickey-Fuller (ADF) test is used to examine the unit-roots in the return series and the Box-Ljung test is used to test randomness before modeling. Our results shown in Table 2 indicate that the $p$-values in these two tests are less than 0.05 , indicating to the null hypothesis should be rejected and that the hypothesis that the returns are stationary should be accepted. This all confirms the non-existence of autocorrelation. The next step is to determine the best fitting mean equation through the model of Auto Regressive Moving Average (ARMA), and then to do the Box-Ljung test of residuals and ARCH-LM test. According to the Box-Ljung test of residuals whose $p$-value is more than 0.05 , we can accept the model. After building the ARMA model to estimate the mean, the volatility will be modeled by the ARCH model. According to Table 2, the ARCH model is significant ( $p$-values < 0.05), which means we should reject the null hypothesis and accept that there is an ARCH effect in the return of ASSI. Therefore, we can build and apply the GARCH model accordingly.

Table 2. Augmented Dickey-Fuller Test, Box-Ljung Test, and ARCH LM-Test.

\begin{tabular}{clcccc}
\hline Tests & & & & \\
\hline Augmented Dickey-Fuller (ADF) test & Dickey-Fuller & $-9.98^{* *}$ & & \\
Box-Ljung test (residuals) & Chi-squared & $8.57^{* * *}$ & df & 10 \\
ARCH LM test & Chi-squared & $96.44^{* * *}$ & df & 5 \\
\hline
\end{tabular}

Note: ${ }^{* *}$ and ${ }^{* * *}$ represent the significance at the $5 \%$ and $1 \%$ levels, respectively.

In Table 3 is the estimation results of GARCH $(1,1), \operatorname{GARCH}(1,2), \operatorname{GARCH}(2,1), \operatorname{GARCH}(2,2)$ models. The values of AIC, BIC and HQ are minimized under the GARCH $(1,1)$. Additionally, within lag values of 10, 15 and 20, we conduct diagnostic tests by applying the Box-Ljung test and the ARCH LM test to the squared standardized residuals of the GARCH $(1,1)$ model. The outcomes indicate that the selected GARCH $(1,1)$ model is appropriate for the price returns of ASSI, as the hypotheses of no remaining ARCH effects and no autocorrelation cannot be rejected. 
Table 3. Estimation results of GARCH models for ASSI.

\begin{tabular}{|c|c|c|c|c|}
\hline & GARCH $(\mathbf{1}, \mathbf{1})$ & GARCH $(1,2)$ & GARCH $(2,1)$ & GARCH $(2,2)$ \\
\hline Bayesian Information Criterion (BIC) & -5.142757 & -5.137233 & -5.135144 & -5.130149 \\
\hline \multirow[t]{2}{*}{ Box-Ljung test $\left(\mathrm{r}^{\wedge} 2, \operatorname{lag}=10\right)$} & 9.3356 & 8.1959 & 9.2639 & 8.1959 \\
\hline & $(0.5006)$ & $(0.6097)$ & $(0.5073)$ & $(0.6097)$ \\
\hline Box-Ljung test $\left(r^{\wedge} 2\right.$, lag $\left.=15\right)$ & 12.206 & 11.014 & 12.061 & 11.014 \\
\hline Box-Ljung test $\left(r^{\wedge} 2\right.$, lag $\left.=20\right)$ & $(0.5202)$ & $(0.5389)$ & $(0.5230)$ & $(0.5389)$ \\
\hline \multirow[t]{2}{*}{ ARCH LM test $(r$, lag $=10)$} & 9.195 & 8.0594 & 9.1165 & 8.0594 \\
\hline & $(0.5137)$ & $(0.623)$ & $(0.5211)$ & $(0.6230)$ \\
\hline \multirow[t]{2}{*}{ ARCH LM test $(r$, lag = 15) } & 11.943 & 10.712 & 11.833 & 10.712 \\
\hline & $(0.6833)$ & $(0.7728)$ & $(0.6916)$ & $(0.7728)$ \\
\hline
\end{tabular}

Note: 1. $\mathrm{r}$ represents residual; 2. GARCH means Generalized Autoregressive Conditional Heteroskedasticity and ASSI means Airport Shipping Set Index.

The parameters of the GARCH $(1,1)$ model for ASSI returns are positively significant at a $1 \%$ level (Table 4), implying the null hypothesis should be rejected and the existence of volatility clustering in return series should be accepted. More specifically, volatility from the previous periods has the power of explaining the current volatility condition. Thus, the sum of coefficients $\alpha$ and $\beta$ in the GARCH model is a measure of persistence in the volatility shocks; if the result is close to one then the more persistent the stock to conditional variance. However, it appears that the $(\alpha+\beta)$ is around 0.996 which means that the ASSI return series has both attributes: volatility clustering and persistence. Hence, all previously mentioned tests indicate that the variance equation is well characterized and specified.

Table 4. Estimation Results of the GARCH Model in the ASS.

\begin{tabular}{cccc}
\hline Coefficient & Estimate & Std. Error & t Value \\
\hline$\omega$ & 0.00 & 0.00 & $2.44^{* *}$ \\
$\alpha$ & 0.136 & 0.03 & $5.12^{* * *}$ \\
$\beta$ & 0.859 & 0.03 & $33.09^{* * *}$ \\
\hline
\end{tabular}

Note: $1 .{ }^{* *}$ and ${ }^{* * *}$ represent the significance at the $10 \%, 5 \%$ and $1 \%$ levels, respectively; 2 . ASS means Chinese Airport Shipping Set.

Based on the VaR, we can observe in Figure 2 that at the beginning of COVID-19, there was a higher level of maximum possible loss of value and then the VaR value gradually lessens as the outbreak gets under control, indicating that the outbreak affected risk changes and caused the volatility of Chinese ASSI shown (See Figure 2). High volatility indicates high uncertainty in market price and leads to high risks. Hence, the COVID-19 crisis has resulted in market fluctuations that relate to investor uncertainty about the future market environment due to the restrictions put in place. On the other hand, with the pandemic control and airline service restoration, the ASSI is becoming less volatile.

\subsubsection{Robustness Checks}

We consider several alternative specifications of GARCH models to check the robustness of our results. The results demonstrate that findings from alternative specifications of GARCH models appear to be similar to those from the GARCH $(1,1)$ model. We find that VaR values in Figure 3 from alternative specifications appear to be similar in magnitude and trend to those from the baseline specification (See, Figure 3), suggesting that our findings are robust to alternative specifications. 


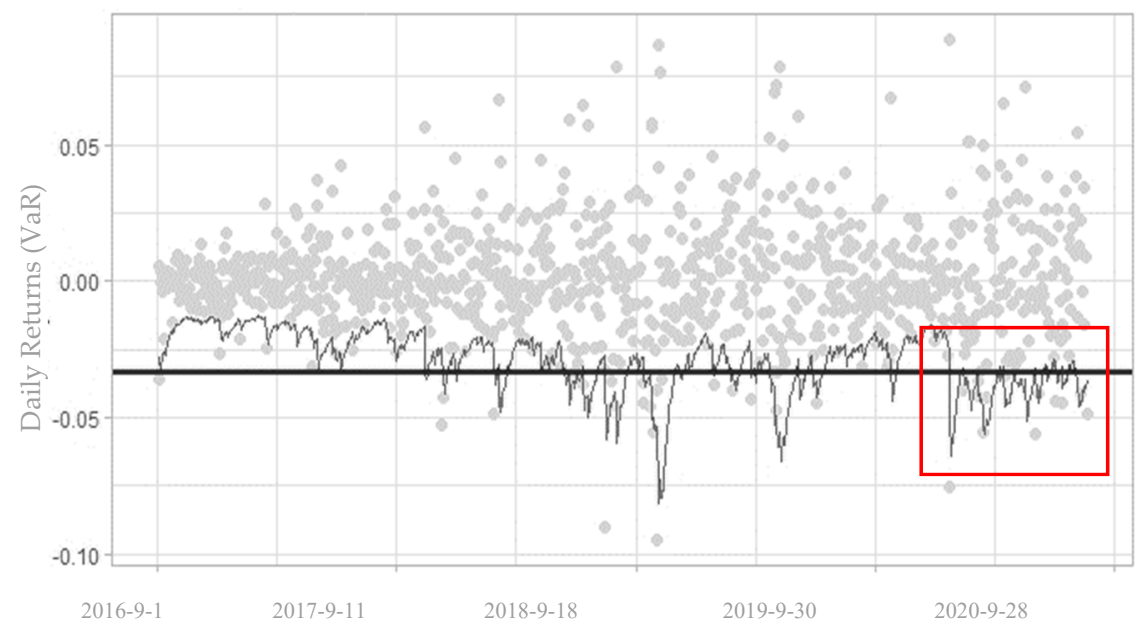

Figure 2. VaR Value of Daily Returns of the Stock Index in the Airport Shipping Set (31 August 2016-1 September 2020) Note: 1 . The fluctuant curve is the VaR outcome of the GARCH model, while the thick black line is the VaR outcome of the normal distribution; 2 . The red box represents the volatility of daily returns of ASSI during the COVID-19 period.

0.05

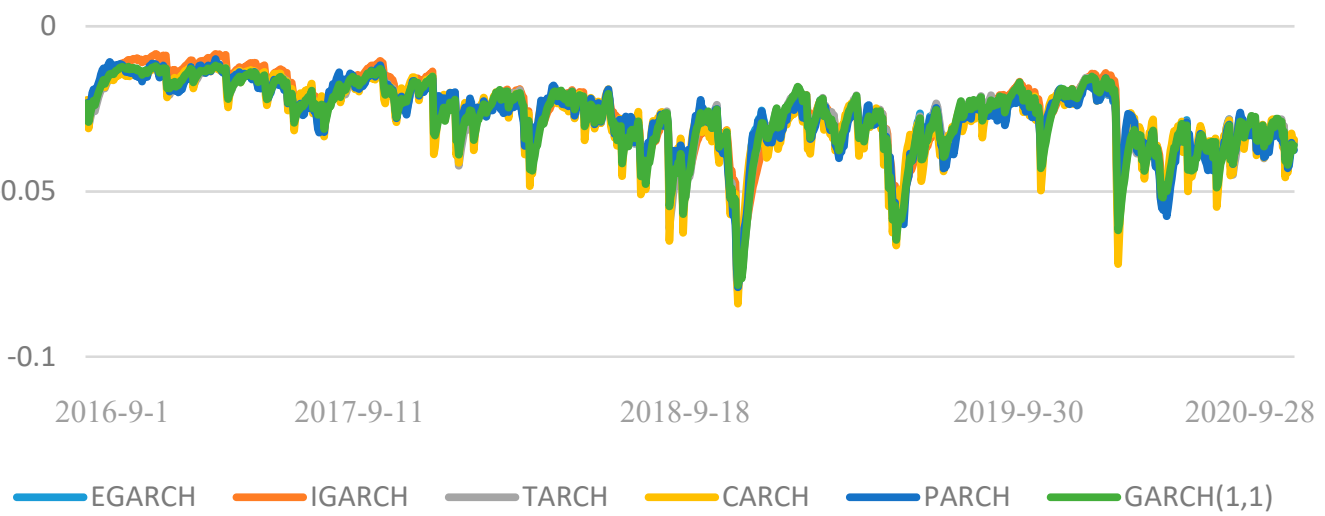

Figure 3. VaR Values of several alternative specifications of GARCH models. (31 August 2016-1 September 2020).

\subsection{Empirical Results of Stock Index of Every Company in the ASS}

In Figure 4 is the trends of daily returns on the stock index for every firm in ASS, and VaR estimates at the $95 \%$ confidence level. As can be seen, the VaR estimations capture the changes in the volatility of the returns during the COVID-19 period. Among airlines, except for Hainan Airlines Holding Co. LTD and CITIC Offshore Helicopter Co., Ltd. who have significant volatility and face larger losses at the beginning of the outbreak, Air China, Eastern Airlines, Southern Airlines and Spring Airlines have similar volatility and potential losses. Although at first their stock indexes were influenced by the pandemic, this impact gradually decreases. More specifically, fluctuation ranges in every firm tend to stable; the maximum potential losses decrease. One reason is related to the pandemic control and shipping increase. Another reason is that airline stocks benefit from the rise of RMB exchange rates and the decrease in oil prices. 


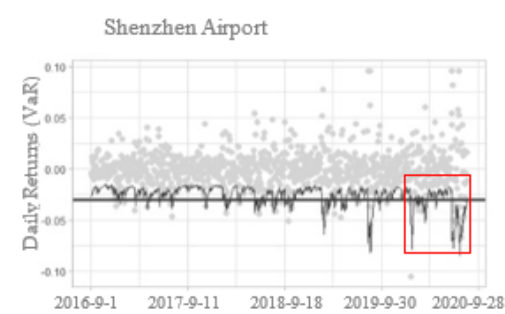

(a)

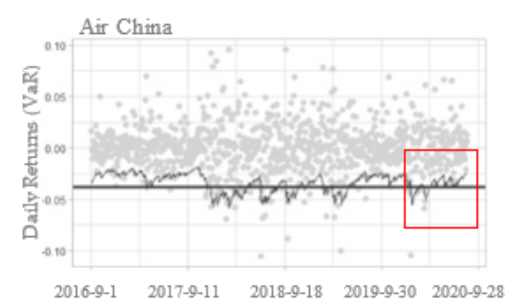

(d)

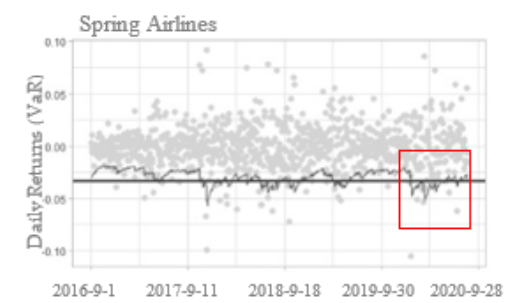

(g)

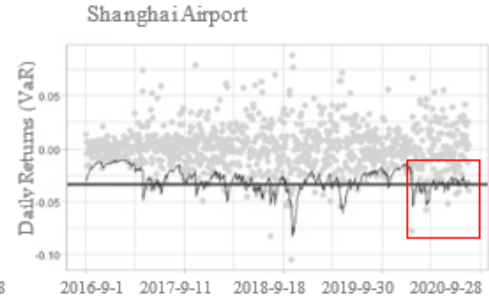

(b)

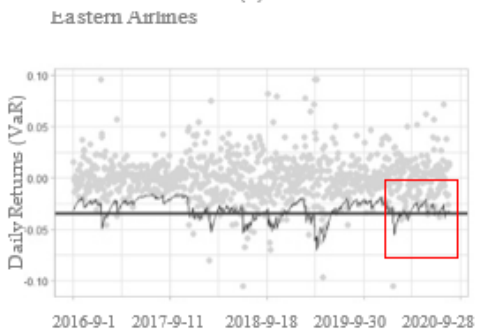

(e)

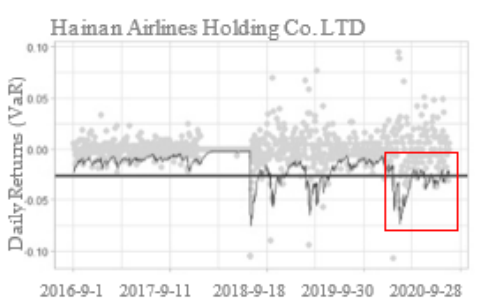

(h)

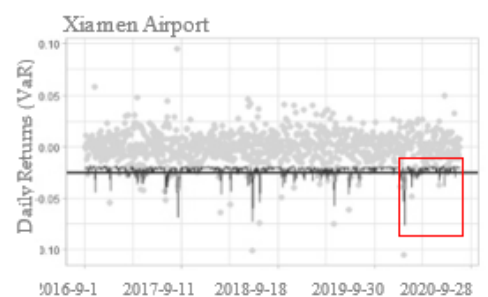

(c)
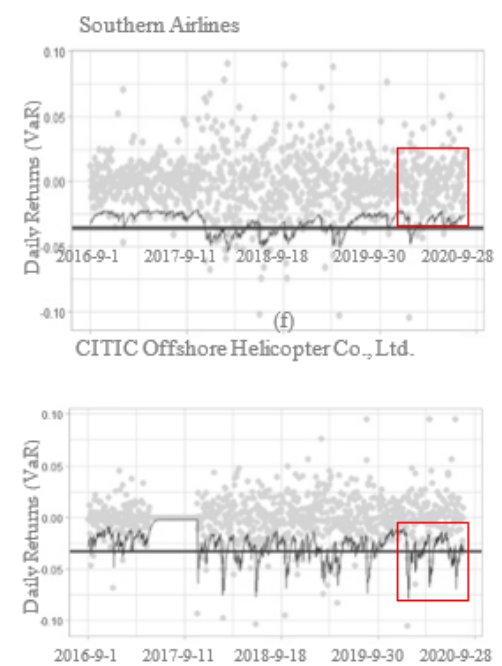

(i)

Figure 4. VaR Value of Daily Returns of the Stock Index in Airline Related Firms (Except for Stocks within No ARCH Effects, 31 August 2016-1 September 2020). Note: 1. The volatility curve is the VaR outcome of the GARCH model, while the thick black line is the outcome of the normal distribution; 2. The red box represents volatility during the COVID-19 period.

In terms of airports, compared to Shenzhen Airport and Xiamen Airport, Shanghai Airport captures the least volatility as well as possible value losses, revealing that Shanghai Airport can better perform risk management. On the other hand, although Shenzhen Airport was dramatically affected at first, its VaR values were less than those of Shanghai Airport between March and June when a large number of measures were introduced for COVID-19 control (See Figure 4a,b), which means that Shenzhen Airport might take effective measures to reduce pandemic risks. To identify these methods of risk management, we conduct the text analysis in Section 3.3 based on half-year reports of Shanghai Airport and Shenzhen Airport. Additionally, we do not show the VaR estimations of Baiyun Airport, China Express and Juneyao Airlines, because the ARCH effects of them are not significant, indicating that we should stop the test.

\subsection{Word Could of Half Reports Related to Epidemic between Shenzhen Airport and Shanghai Airport}

Depending on word frequency, word clouds show keywords within various sizes in Figure 5. The larger keywords are, the higher their frequencies are. From Figure $5 a, b$, We can quickly identify the similarities and differences between Shenzhen Airport and Shanghai Airport when these two firms faced COVID-19. The most frequent words are "epidemic" in the two firms, occurring 54 times in Shenzhen Airport as well as 41 times in Shanghai Airport, indicating that COVID-19 definitely has a serious impact on airport business. "Company", "Effect", "Pneumonia" and "Novel coronavirus" with higher frequencies shown in the word clouds also support these negative effects. More specifically, based on the semiannual financial reports, the pandemic had a severe impact on revenues and net profits. Compared to the previous numbers, the operating revenues were down $31.03 \%$ in Shenzhen Airport and 50.8\% in Shanghai Airport year on year, and the net profits decreased by $149.16 \%$ in 
Shenzhen Airport and $114.29 \%$ in Shanghai Airport year on year. Therefore, the Word Cloud and semiannual financial reports further support our empirical results in Section 3.2 that COVID-19 caused stock volatility and has negative impacts on corporate businesses.

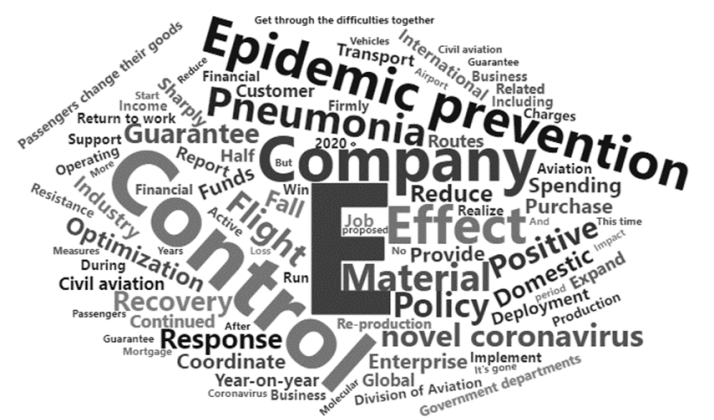

(a)

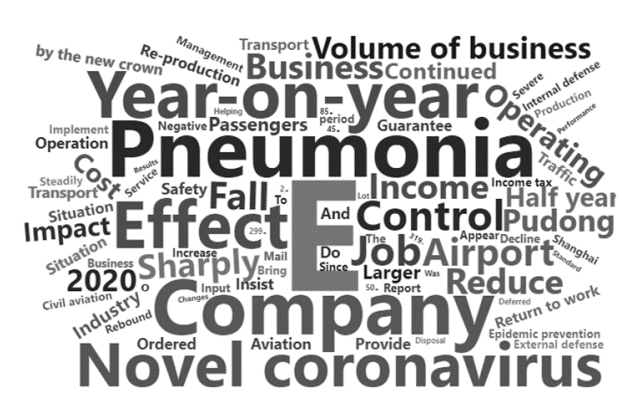

(b)

Figure 5. (a) Word Clouds Related to Epidemic in the Semiannual Report of Shenzhen Airport. (b) Word Clouds Related to Epidemic in the Semiannual Report of Shanghai Airport. Note: E means epidemic.

On the other hand, from the word cloud, we can also find different responses to the outbreak between Shenzhen Airport and Shanghai Airport. Compared to Shanghai Airport, Shenzhen Airport more positively dealt with the novel coronavirus. From Figure 5b, we can see the negative effects of COVID-19 on Shanghai Airport (see Figure 5b "Fall", "Sharply", "Reduce". For example, passenger throughput decreased in transport and catering sales (see Figure 5b "Volume of Business", "Operating", "Business"), which crucially impacts performance (see Figure $5 b$ "Income"). Though there is little information on the pandemic response, it is hard to say that this corporation does little when facing the outbreak. We assume that we have not gained more comprehensive data to help us make investment decisions. This also supports the empirical results shown in Figure $4 \mathrm{~b}$ that there is more stable volatility of VaR values after the epidemic outbreak.

From Figure 5a, we can quickly find "Epidemic prevention", "Control", "Response", "Guarantee", and "Material", indicating that although this company has been attacked, it has taken positive measures to reduce harmful effects and optimize operation. For example, based on the semiannual financial report, first, in the governmental ties, this company has responded to the national call for better epidemic prevention and control; then it took the initiative to make breakthroughs in policy resources, issued preferential charging policies, and coordinated government agencies to tide over the difficulties (see Figure 5a "Policy", "Government department"). Second, to deal with negative effects on handling capacity, Shenzhen airport partly transfers passenger transport into freight transport as well as open green channels for the import and export of epidemic prevention materials (see Figure 5a "Expand"). Third, Shenzhen Airport also builds good relationships with cooperative partners. It jointly builds an air-land combined transport platform with Bus Group to explore inter-city carpooling services (see Figure 5a "Expand"), and exempts the rent and management fees for their rent customers, so as to effectively reduce the operating pressure on the tenants (see Figure $5 a$ "Coordinate"). As a result, Shenzhen Airport can quickly recover from the outbreak hit (see Figure 5a "Recovery"), which is also consistent with the volatility results in Section 3.2 (see Figure 4a) that VaR values had a significant decrease after the epidemic outbreak.

\section{Discussion and Implications}

This study responds to calls for more attention to how COVID-19 impacts the airline industry in the financial market (Goodell 2020). We investigate the stock index volatility of Chinese airlines during the pandemic period and what future implications it will have for risk management. To better understand the volatility during the COVID-19 period, we estimate the holistic volatility of ASSI, the volatility of stock index in every firm in ASSI, and different word clouds between Shenzhen Airport and Shanghai Airport. 


\subsection{Theoretical Implications}

Our investigation enriches research on the airline industry in the financial market during the outbreak. First, the COVID-19 crisis has resulted in market volatility in the airline sectors in China, which relates to investor uncertainty about the future market environment due to the restrictions put in place. There was increasing volatility during COVID-19 compared to the pre-pandemic period, which is similar to previous studies that the COVID-19 outbreak causes unprecedented effects of the US stock market volatility whose degrees exceed those during the October 1987 and December 2008 crash (Sharif et al. 2020). This outcome is consistent with previous research into airline stock price volatility regarding past global crisis periods such as SARS. Depending on the research from Pearce (2020), a turning point in Chinese domestic air travel happened after three months of SARS, which showed a sharp V-shape but there was no recession. Loh (2006) found that airline stocks are more sensitive to news about SARS and surfaced in the form of increased volatilities. This suggests that the increased volatility results in higher financial risk. With the pandemic control and airline service restoration, the ASSI is becoming less volatile. Moreover, there was a higher level of maximum possible loss of value and then the VaR value gradually lessens as the outbreak gets under control, indicating that the outbreak affected risk changes and caused the volatility of Chinese ASSI shown.

Second, several airlines experienced significant volatility at the beginning of the outbreak as a result of the global lockdowns. In the ASS, the volatility of airport stocks has crucial differences while the volatility of shipping stocks is similar. Third, to offset the decline in demand and revenue, airlines have adopted several rationalization policies and managerial tactics. The word cloud figures reveal that there are different responses to the pandemic between Shenzhen Airport and Shanghai Airport shown in their semiannual financial reports. Shenzhen Airport had a more positive attitude and took various measures to mitigate risks and to recover, supporting that its VaR values had a significant decrease after the epidemic outbreak.

Our research provides new insight into research on volatility estimation. First, we expand research on volatility estimation from the macro-level (the holistically financial market or the industry) into the micro-level (enterprise management of several firms). From the different reports in risk management between Shenzhen Airport and Shanghai Airport, we can identify that corporation activities influence their stock indexes to some extent. The research combining finance with management expands the research boundaries of finance into the management field. Second, based on volatility estimation at the macro-micro level, we also provide a novel research method. The usage of combination methods (GARCH and text mining) is inspired by the Combination Principle of TRIZ that is applied to solve invention problems in physics and chemistry, extending natural science methods into the financial and managerial areas. Although the GARCH model and text mining have been used in a wider range, little literature combines these two. Our study primarily tries to combine the GARCH model with text mining to realize the volatility research at the industry-enterprise level.

\subsection{Practical Implications}

This paper offers practical suggestions for companies and investors. Concerning short term recovery, although hit by the crisis, enterprises need to alter managerial and operational ways to quickly respond to the crisis, contributing to stock indexes upswing. For managers, first, the survival and recovery of their business are largely based on their risk management. Having a strong internal policy will be paramount in managing risks and reducing the negative effects of risks on their stock indexes. Such as Shenzhen Airport, to deal with negative effects on handling capacity, it partly transferred passenger transport into freight transport as well as opened green channels for the import and export of epidemic prevention materials. Second, it is crucial to building good relationships with governments and cooperative partners. In terms of ties with governments, companies in China should positively respond to the national call and coordinate government agencies to overcome difficulties over a difficult period. In terms of cooperative partners, companies can join with partners to explore 
new services and support their partners such as exempting the rent and instituting management fees for their rent customers.

In long term development, except for striving to gradually improve management and operation of business to enhance investors' expectation and confidence, boosting firms' stock prices and prompting to better develop in the capital market, companies should pay more attention to the information of financial disclosure that makes investors better acknowledge business situations. Therefore, the third suggestion is that companies should provide more information for investors. Airlines must work to re-establish consumer confidence by taking proactive safety measures including maintaining social distancing, implementing appropriate hygiene measures and offering flexibility with bookings to incentivize an uptake in demand. This will not only help investors make investment decisions but also mitigate the adverse effects of risks to increase consumer confidence. The return to financial stability is reliant upon consumer confidence.

\subsection{Limitation and Future Research}

Like most research, this study suffers from several limitations that provide avenues for future research. As for the comparative study, first, this study only investigates the different volatility between stock indexes of firms. From Figure $4 \mathrm{~d}-\mathrm{g}$, we can see similar volatility among shipping firms. Future studies can use the text analysis method (the cosine similarity method is used to calculate the similarity to identify similar measures) for risk reduction among these firms. Second, this article conducts a cross-enterprise comparative study, but from Figure $4 a$, we can see that there is significant volatility in the stock indexes of Shenzhen Airport after June 2020. Due to no release of its third-quarter report when we write this article, we cannot analyze the reasons caused by the regional outbreak or others. In the future, studies can do a longitudinally comparative study to further discuss the impacts of COVID-19 on firms in the airline sector.

Moreover, although we find risk reduction activities conducted by firms can lessen VaR values to some extent, we cannot figure out the mechanism between risk management activities and volatility, or the effects of contents in financial reports on volatility, which needs to be investigated in the future. First, among the risk mitigation measures, business improvement and relationships with governments and partners are mentioned. Future research can do quantitative analysis to investigate relations between business improvement and volatility of stock indexes as well as between relationships (firms, governments and partners) and volatility of stock indexes, which would not only provide reliable evidence for our results but also enrich research on organization and government. Second, investors depend on financial reports to make an investment decision. There are several investigations on information disclosure: how do firms do information disclosure; whether information disclosure has an influence on the volatility of stock indexes; what kind of information does cause what kind of volatility to the index.

\section{Conclusions}

As stringent travel regulations have resulted in a fall in demand, the aviation industry has suffered greatly. Prior research has been inconclusive on the impacts of the COVID-19 pandemic on the aviation industry. This paper addresses the debate by observing the implications of the COVID-19 pandemic on the Chinese aviation industry based on their stock indexes in ASS. Our study goes beyond the volatility estimation at the macro level developed in prior research and expands research on volatility estimation into the enterprise micro level. Based on the GARCH model, we find that although the stock index volatility has been confirmed to have increased, it is suggested that the risk of returns on the stock price decreased in the long-term as stock prices are continuing to rebound. Moreover, every stock index in every firm shows that the volatility of airport stocks has significant differences while the volatility of shipping stocks is similar. Although the stock price volatility has been confirmed to have increased, it is suggested that the risk of returns on the stock price decreased in the long-term as stock prices are continuing to rebound. Drawing on the text mining technique, we compare the 
different risk reduction behavior between firms based on their volatility difference. From the word cloud views from semiannual financial reports, we find that Shenzhen Airport and Shanghai Airport respond differently to the pandemic. The former firm had a more positive attitude and took various measures to mitigate risks, providing evidence of volatility differences and of significant decreases of VaR values in Shenzhen Airport after the epidemic outbreak.

It is therefore proposed that future research within the aviation industry can focus on the following research. First, a holistically comparative study could be used to identify similar risk-reduced behavior among firms by text analysis method (the cosine similarity method is used to calculate the similarity to identify similar measures). Second, a longitudinally comparative study could be used to identify the effects of the development of the pandemic on the volatility of the stock indexes in one firm. Third, a quantitative analysis could be used to investigate relations between business improvement and volatility of stock indexes as well as between relationships (firms, governments and partners) and volatility of stock indexes. Four, the research could be focused on relations of information disclosure and volatility of stock indexes.

Author Contributions: Conceptualization and methodology, J.L., P.Q., J.D., L.H., E.H.H., E.M.S., I.R. and H.Z.; Data curation, J.L. and E.H.H.; Formal analysis, J.D., P.Q, J.L. and L.H.; Resources, J.L., L.H., E.H.H., E.M.S., I.R., J.D. and H.Z.; Software, J.L., J.D., H.Z., and P.Q.; Visualization, J.L. and P.Q.; writing—original draft preparation, J.L., L.H., E.H.H., E.M.S., I.R.; writing—review and editing, J.L., P.Q., J.D.,E.M.S., I.R. and H.Z.; funding acquisition, P.Q. All authors have read and agreed to the published version of the manuscript.

Funding: This research received no external funding.

Acknowledgments: All authors gratefully acknowledge support from Xue-Feng Shao. All authors would like to thank him for careful supervision and comments which greatly improved the paper. Additionally, all authors are grateful to editors for their time and assistance on relevant work of manuscript submission, revision, acceptance, proofreading and publication. Finally, we strongly appreciate reviewers who provide constructive suggestions that inspire our ideas and improve the article.

Conflicts of Interest: The authors declare no conflict of interest.

\section{References}

Akhtaruzzaman, Md, Sabri Boubaker, Mardy Chiah, and Angel Zhong. 2020a. COVID-19 and Oil Price Risk Exposure. Available online: https://ssrn.com/abstract=3650151 (accessed on 21 May 2020).

Akhtaruzzaman, Md, Sabri Boubaker, Brian M Lucey, and Ahmet Sensoy. 2020b. Is Gold a Hedge or Safe Haven Asset during COVID-19 Crisis? Available online: https://ssrn.com/abstract=3621358 (accessed on 21 May 2020). [CrossRef]

Akhtaruzzaman, Md, Sabri Boubaker, and Ahmet Sensoy. 2020c. Financial contagion during COVID-19 crisis. Finance Research Letters, 101604. [CrossRef]

Angelidis, Timotheos, Alexandros Benos, and Stavros Degiannakis. 2004. The use of GARCH models in VaR estimation. Statistical Methodology 1: 105-28. [CrossRef]

Ardia, David, Keven Bluteau, and Maxime Rüede. 2019. Regime changes in Bitcoin GARCH volatility dynamics. Finance Research Letters 29: 266-71. [CrossRef]

Australian Department of Health. 2019. Coronavirus (COVID-19) Health Alert. Available online: https://www. health.gov.au/news/health-alerts/novel-coronavirus-2019-ncov-health-alert (accessed on 21 May 2020).

Bollerslev, Tim. 1986. Generalized autoregressive conditional heteroskedasticity. Journal of Econometrics 31: 307-27. [CrossRef]

Chen, Yi-Wen, Chu-Bin Lin, and Anthony H Tu. 2019. Regime-Switching Processes and Mean-Reverting Volatility Models in Value-at-Risk Estimation: Evidence from the Taiwan Stock Index. Emerging Markets Finance and Trade 56: 1-18. [CrossRef]

Chin, Ken Lee, Richard Ofori-Asenso, Kaylee A. Jordan, Daryl Jones, and Danny Liew. 2020. Early signs that COVID-19 is being contained in Australia. The Journal of Infection. in press. [CrossRef]

Claussen, Jorg, Christian Essling, and Christian Peukert. 2018. Demand variation, strategic flexibility and market entry: Evidence from the U.S. airline industry. Strategic Management Journal 39: 2877-98. [CrossRef]

Donthu, Naveen, and Anders Gustafsson. 2020. Effects of COVID-19 on Business and Research. Journal of Business Research 117: 284-89. [CrossRef] 
Engle, Robert F. 1982. Autoregressive conditional heteroscedasticity with estimates of the variance of United Kingdom inflation. Conometrica: Journal of the Econometric Society 50: 987-1007. [CrossRef]

Fan, Di, Yi Li, Wei Liu, Xiao-Guang Yue, and Georgios Boustras. 2020. Weaving public health and safety nets to respond the COVID-19 pandemic. Safety Science 134: 105058. [CrossRef]

Goodell, John W. 2020. COVID-19 and finance: Agendas for future research. Finance Research Letters, 101512. [CrossRef]

Gössling, Stefan, Daniel Scott, and C. Michael Hall. 2020. Pandemics, tourism and global change: A rapid assessment of COVID-19. Journal of Sustainable Tourism 29: 1-20. [CrossRef]

Han, Yan, Xue-Feng Shao, Xin Cui, Xiao-Guang Yue, Kelvin Joseph Bwalya, and Otilia Manta. 2019. Assessing Investor Belief: An Analysis of Trading for Sustainable Growth of Stock Markets. Sustainability 11: 5600. [CrossRef]

He, Hongwei, and Lloyd Harris. 2020. The impact of Covid-19 pandemic on corporate social responsibility and marketing philosophy. Journal of Business Research 116: 176-82. [CrossRef] [PubMed]

$\mathrm{He}, \mathrm{Wu}$, Shenghua Zha, and Ling Li. 2013. Social media competitive analysis and text mining: A case study in the pizza industry. International Journal of Information Management 33: 464-72. [CrossRef]

Heimerl, Florian, Steffen Lohmann, Simon Lange, and Thomas Ertl. 2014. Word cloud explorer: Text analytics based on word clouds. Paper presented at 2014 47th Hawaii International Conference on System Sciences, Waikoloa, HI, USA, January 6-9.

Huang, Chaolin, Yeming Wang, Xingwang Li, Lili Ren, Jianping Zhao, Yi Hu, Li Zhang, Guohui Fan, Jiuyang Xu, Xiaoying Gu, and et al. 2020. Clinical features of patients infected with 2019 novel coronavirus in Wuhan, China. The Lancet 395: 497-506. [CrossRef]

Katsiampa, Paraskevi. 2017. Volatility estimation for Bitcoin: A comparison of GARCH models. Economics Letters 158: 3-6. [CrossRef]

Liu, Wei, Xuefeng Shao, Marco De Sisto, and Wen Helena Li. 2020a. A New Approach for Addressing Endogeneity Issues in the Relationship Between Corporate Social Responsibility and Corporate Financial Performance. Finance Research Letters, 101623. [CrossRef]

Liu, Wei, Xiao-Guang Yue, and Paul B Tchounwou. 2020b. Response to the COVID-19 Epidemic: The Chinese Experience and Implications for Other Countries. International Journal of Environmental Research and Public Health 17: 2304. [CrossRef]

Loh, Elaine. 2006. The impact of SARS on the performance and risk profile of airline stocks. International Journal of Transport Economics 33: 401-22.

Meyer, David, Kurt Hornik, and Ingo Feinerer. 2008. Text mining infrastructure in R. Journal of Statistical Software 25: 1-54. [CrossRef]

Pearce, Brian. 2020. IATA Economic Reports: COVID-19 Updated Impact Assessment of the Novel Coronavirus. Available online: https:/www.iata.org/en/iata-repository/publications/economic-reports/ coronavirus-updated-impact-assessment/ (accessed on 21 May 2020).

Qiu, Yun, Xi Chen, and Wei Shi. 2020. Impacts of social and economic factors on the transmission of coronavirus disease 2019 (COVID-19) in China. Journal of Population Economics 33: 1127-72. [CrossRef]

Shaked, Israel, and Brad Orelowitz. 2020. The airline industry and COVID-19: Saving for a rainy day. American Bankruptcy Institute Journal 39: 36-37, 57-58.

Sharif, Arshian, Chaker Aloui, and Larisa Yarovaya. 2020. COVID-19 pandemic, oil prices, stock market, geopolitical risk and policy uncertainty nexus in the US economy: Fresh evidence from the wavelet-based approach. International Review of Financial Analysis 70: 101496. [CrossRef]

Slater, Adam. 2020. The economic cost of coronavirus lockdowns. Oxford Economics 44: 17-19.

Wang, Chaolong, Li Liu, Xingjie Hao, Huan Guo, Qi Wang, Jiao Huang, Na He, Hongjie Yu, Xihong Lin, An Pan, and et al. 2020. Evolving epidemiology and impact of non-pharmaceutical interventions on the outbreak of coronavirus disease 2019 in Wuhan, China. JAMA 323: 1915-23.

Worldometer. 2020. COVID-19 Coronavirus Pandemic. Available online: https://www.worldometers.info/ coronavirus/ (accessed on 21 May 2020). 
Yue, Xiao-Guang, Xue-Feng Shao, Rita Yi Man Li, M James C Crabbe, Lili Mi, Siyan Hu, Julien S Baker, and Gang Liang. 2020a. Risk management analysis for novel Coronavirus in Wuhan, China. Journal of Risk and Financial Management 13: 22. [CrossRef]

Yue, Xiao-Guang, Xue-Feng Shao, Rita Yi Man Li, M James C Crabbe, Lili Mi, Siyan Hu, Julien S Baker, Liting Liu, and Kechen Dong. 2020b. Risk Prediction and Assessment: Duration, Infections, and Death Toll of the COVID-19 and Its Impact on China's Economy. Journal of Risk Financial Management 13: 66. [CrossRef]

Publisher's Note: MDPI stays neutral with regard to jurisdictional claims in published maps and institutional affiliations.

(C) 2020 by the authors. Licensee MDPI, Basel, Switzerland. This article is an open access article distributed under the terms and conditions of the Creative Commons Attribution (CC BY) license (http://creativecommons.org/licenses/by/4.0/). 